\section{REDUCTION OF PANCREATIC ANASTOMOTIC LEAKAGE AFTER PANCREATICODUODENECTOMY}

I have had two letters to the editor published in Annals of Surgery ${ }^{1,2}$ regarding a technique for prevention of fistula after pancreaticoduodenectomy, one in 2008 and one in 2013, presenting a small personal series without fistula complication. In this series, the invagination technique was used with an internal catheter stent in the pancreatic duct and three non-absorbable sutures through the pancreatic tissue just proximal to the end of the stump. This technique prevents pancreatic enzymes being present at the anastomotic site, which may be an important factor in the prevention of fistula.
Since these publications I have seen several publications where the fistula rate was reduced to $10 \%$, and a recent large study stated that postoperative pancreatic fistula remains a troublesome complication after pancreaticoduodenectomy with no clear consensus regarding the ideal method of pancreaticoenteric anastomosis. ${ }^{3-5}$

A study by a high-volume centre to duplicate the technique described in the small personal series to ascertain if the good results are duplicated would be useful and warranted.

\section{Paul Niloff, MD}

Affiliation: Associate professor of surgery (retired), McGill University, Montreal, Que.

DOI: $10.1503 / c j s .1861021$

\section{References}

1. Niloff P. Reduction of pancreatic anastomotic leakage after pancreaticoduodenectomy. Ann Surg 2008;248:497-8.

2. Niloff P. Prevention of pancreatic fistula after pancreatico-duodenectomy. Ann Surg 2013;60:17.

3. Shrikhande S, Sivasanker M, Vollmer CM, et al. Pancreatic anastomosis after pancreaticoduodenectomy: a position statement by the International Group of Pancreatic Surgery (ISGPS). Surgery 2017;161:1221-34.

4. Piedimonte S, Wang Y, Bergman S, et al. Early experience with robotic pancreatic surgery in a Canadian institution. Can $\mathcal{F}$ Surg 2015;58:394-401.

5. Kakaei F, Beheshtirouy S, Nejatollahi SM, et al. Effects of adding Braun jejunojejunostomy to standard Whipple procedure on reduction of afferent loop syndrome a randomized clinical trial. Can 7 Surg 2015;58:383-8. 